Modeling of dangerous phenomena and innovative techniques for hazard evaluation and risk mitigation

Giulio lovine $^{\mathrm{a}}$, Christoph Aubrecht ${ }^{\mathrm{bc}}$, Thomas Glade ${ }^{\mathrm{d}}$, Johannes Hübl ${ }^{\mathrm{e}}$ \& Manuel Pastor ${ }^{f}$ 


\section{Modeling of dangerous phenomena and innovative techniques for hazard evaluation and risk mitigation}

Society is frequently exposed to and threatened by dangerous phenomena in many parts of the world

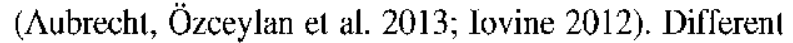
types of such phenomena require specific actions for proper risk management, from the stages of hazard identification to those of mitigation (including monitoring and early-warning) and/or reduction. The understanding of both predisposing factors and triggering mechanisms of a given danger and the prediction of its evolution from the source to the overall affected zone are relevant issues that must be addressed to properly evaluate a given hazard. Any assessment of potential damage should take into account the vulnerability of the elements at risk, present and expected, and possibly its varying spatial and temporal characteristics (Aubrecht et al. 2012; Aubrecht, Özceylan et al. 2013), including social, environmental, and structural components (Birkmann et al. 2013). Total risk evaluations should be carried out attentively on respective appropriate scales as facilitated by the quality of underlying input data and should provide supporting information for optimal selections of mitigation and/or reduction measures, based on expected impact scenarios, e.g. by comparison with past patterns (Aubrecht and Özceylan 2013).

Past disasters usually provide precious lessons that, combined with a proper planning of social settlements, may allow to minimizing the impact of future events. In fact, as the zero risk option is unrealistic, innovative approaches can be adopted to minimizing the residual risks, including integrated modeling and monitoring of hazardous phenomena, vulnerability evaluations and land use planning, knowledge dissemination and risk communication, and adoption of remedial measures (Aubrecht et al, in press). In case an area at risk is threatened by different types of phenomena, the evaluation of the overall risk and its mapping results becomes more complex (Kappes et al. 2012).

In the past decades, several approaches for risk evaluation have been proposed: qualitative and quantitative techniques have been tested against real case studies, at local or regional scales; modeling and sensitivity analyses have become more popular (Crisci et al. 2008; Iovine 2008); and real-time monitoring systems have become widespread, thus supporting warning procedures for civil protection purposes (Iovine et al. 2010; Capparelli et al. 2012). In this regard, some examples have recently been discussed in guest-edited special issues of relevant scientific joumals ( $\Lambda$ ubrecht, Fuchs, and Neuhold 2013; Iovine, Di Gregorio, and Sheridan 2006; Iovinc, Sheridan, and Di Gregorio 2006; Iovine et al. 2007, 2012; Iovine and Sheridan 2009a, 2009b; Iovine, Pastor, and Sheridan 2010; Iovine, Huebl et al. 2010; Parise and Iovine 2009; Parise et al. 2012).

The present special issue offers a selection of studies that cover a quite large spectrum of topics related to hazard evaluation and risk mitigation, including early warning and planning issues. Two out of five papers deal with modeling/simulation of slope movements, mainly focusing on run-out predictions. A third paper is focused on early warning of atmospheric hazards, while the remaining two deal with modeling of earthquake activity, and with problems of building reconstruction in urbanized sectors threatened by fires.

More in detail, Iannacone and co-workers discuss an example of simulation and sensitivity analysis of run out related to five different scenarios of failure of an active rockslide threatening a village in South Tyrol (Italy). Results obtained by varying friction and turbulent coefficients pointed out that, despite a large variability in the obtained values of run out, risk scenarios do not vary significantly except in the smallest case of failure. On the other hand, in the paper by Sanchez and coworkers (2013), a method to predict the propagation of short run out landslides is presented. The approach relies on a depth-integrated mathematical model including the coupling of soil skeleton and pore fluids, on suitable rheological relationships and on a meshless numerical method which separates the set of computational nodes from the one used to describing topographic features. Model validation is discussed by considering two examples with analytical solutions, and applied to two real cases occurred in Hong Kong in 1995.

Nastos and Matsangouras (2013) describe an early warning system for atmospheric hazards like storms, lightings, galc winds, snow, hail, tornadocs, low tcmperatures, and heat waves. It is intended to be used by local authorities for properly organizing and implementing plans to prevent and mitigate the impacts on humans and constructions. The system is linked to extensive Geographical Information Systems datasets and tools to 
allow for safety planning to mitigate the impacts of extreme atmospheric events. It involves high-resolution numerical modeling, networks for ground observation and lightning detection, and satellite data.

The study by Kechaidou and co-workers (2013) deals with earthquake data analysis in regions of Greece characterized by different seismicity levels. A new model is proposed based on evolutionary computation methods, such as symbolic regression by genetic programming and genetic algorithms to analyze hidden mathematical relations and patterns in seismological signals. The model is calibrated by reverse engineering, closing the loop from data collection to initial hypothesis. Geodynamic properties of the considered regions of Greece emerge from simulation results, in qualitative and quantitative terms.

In Osaragi's (2013) paper, the amelioration of building fireproofing is discussed, as the risk of widespread fires caused by severe earthquakes is extremely high in the Tokyo metropolitan area. A stochastic model is proposed to describe the conversion process of existing structures to eliminating the most hazardous sectors. Time-series changes in structure of a study district are simulated by applying extant urban planning and building codes. Piecemeal efficiency of regulations and their overall effectiveness in ameliorating fire risk in potentially hazardous zones are then commented.

The collection of papers of this special issue offers an interesting perspective on some recent approaches to risk analysis, and a particular focus on hazard issues with reference to different dangerous phenomena. Potentials and limits of the considered approaches can be inferred from the case studies and the related discussions. A generalized adoption of standard approaches for model evaluation and testing - as recently discussed by D'Ambrosio et al. (2013) - is still, unfortunately, only partially found in this field of research; if widely adopted, it may allow to better clarifying potentials and limits of the proposed techniques, thus permitting more sound applications.

\section{References}

Aubrecht, C., S. Freire, C. Neuhold, A. Curtis, and K. Steinnocher. 2012. "Introducing a Temporal Component in Spatial Vulnerability Analysis." Disaster Advances 5 (2): $48-53$.

Aubrecht, C., S. Fuchs, and C. Neuhold. 2013. "Spatiotemporal Aspects and Dimensions in Integrated Disaster Risk Management." Natural Hazards 68 (3): 1205-1216. doi:10.1007/s11069-013-0619-9.

Aubrecht, C., and D. Özceylan. 2013. "Identification of Heat Risk Patterns in the U.S. National Capital Region by Integrating Heat Stress and Related Vulnerability." Environment International 56: 65-77. doi:10.1016/j.envint. 2013.03.005.
Aubrecht, C., D. Özceylan, K. Steinnocher, and S. Freire. 2013. "Multi-level Geospatial Modeling of Human Exposure Patterns and Vulnerability Indicators." Natural Hazards 68 (1): 147-163. doi:10.1007/s11069-012-0389-9.

Aubrecht, C., D. Özceylan Aubrecht, J. Klerx, and S. Freire. in press "Future-oriented Activities as a Concept for Improved Disaster Risk Management." Disaster Advances 7 (1).

Birkmann, J., O. D. Cardona, M. L. Carreño, A. H. Barbat, M. Pelling, S. Schneiderbauer, S. Kienberger, et al. 2013. "Framing Vulnerability, Risk and Societal Responses: The MOVE Framework." Natural Hazards 67 (2): 193-211. doi:10.1007/s11069-013-0558-5.

Capparelli, G., P. Iaquinta, G. Iovine, O. G. Terranova, and P. Versace. 2012. "Modelling the Rainfall-induced Mobilization of a Large Slope Movement in Northern Calabria." Natural Hazards 61 (1): 247-256. doi:10.1007/s11069010-9651-1.

Crisci, G. M., G. Iovine, S. Di Gregorio, and V. Lupiano. 2008. "Lava-flow Hazard on the SE Flank of Mt. Etna (Southern Italy)." Journal of Volcanology and Geothermal Research 177 (4): 778-796. doi:10.1016/j.jvolgeores.2008.01.041.

D'Ambrosio, D., W. Spataro, R. Rongo, and G. G. R. Iovine. 2013. "Genetic Algorithms, Optimization, and Evolutionary Modeling." In Treatise on Geomorphology, vol. 2, Quantitative Modeling of Geomorphology, edited by J. F. Shroder and A. C. W. Baas, 74-97. San Diego, CA: Academic Press.

Iannacone, J. P., B. Q. Luna, and A. Corsini. 2013. "Forward Simulation and Sensitivity Analysis of Run Out Scenarios Using MassMov2D at the Trafoi rockslide (South Tyrol, Italy)." Georisk 7 (4): 240-249.

Iovine, G. 2008. "Mud-flow and Lava-flow Susceptibility and Hazard Mapping Through Numerical Modelling, GIS Techniques, Historical and Geoenvironmental Analyses." In Proceedings of the iEMSs Fourth Biennial Meeting: International Congress on Environmental Modelling and Software, edited by M. Sànchez-Marrè, J. Béjar, J. Comas, A. E. Rizzoli, and G. Guariso, 1447-1460. Barcelona: International Environmental Modelling and Software Society.

Iovine, G. 2012. "Some Considerations on Available Approaches to Risk Mitigation." Geology \& Geosciences 1 (2). OMICS Publishing Group. ISSN: 2329-6755. doi:10.4172/2329-6755.1000e107.

Iovine, G., S. Di Gregorio, and M. F. Sheridan. 2006. "Preface. Hazard Evaluation and Mapping Through Modeling and Simulations." Computational Geosciences 10 (2): 159 160. doi:10.1007/s10596-005-9016-0.

Iovine, G., S. Di Gregorio, M. F. Sheridan, and M. Miyamoto. 2007. "Preface. Modelling, Computer-assisted Simulations and Mapping of Dangerous Phenomena for Hazard Assessment.” Environmental Modelling \& Software 22 (10): 1389-1391. doi:10.1016/j.envsoft.2006.12.002.

Iovine, G., J. Huebl, M. Pastor, and M. F. Sheridan. 2010. "Outcomes of the Special Issue on Approaches to Hazard Evaluation, Mapping, and Mitigation." Natural Hazards and Earth Systems Sciences 11: 2433-2436. doi:10.5194/ nhess-11-2433-2011.

Iovine, G., P. Lollino, S. L. Gariano, and O. G. Terranova. 2010. "Coupling Limit Equilibrium Analyses and Realtime Monitoring to Refine a Landslide Surveillance System in Calabria (Southern Italy).” In Special Issue on Approaches to Hazard Evaluation, Mapping, and 
Mitigation, edited by G. Iovine, J. Huebl, M. Pastor, and M. F. Sheridan, Göttingen: Copernicus GmbH (Copernicus Publications), ISSN: 1561-8633. Natural Hazards and Earth System Sciences 10: 2341-2354.

Iovine, G., M. Pastor, and M. F. Sheridan. 2010. "Preface. Modelling and Simulation of Dangerous Phenomena, and Innovative Techniques for Hazard Mapping and Mitigation." Physics and Chemistry of the Earth 35 (3-5): 125126. doi:10.1016/j.pce.2010.05.003.

Iovine, G., and M. F. Sheridan. 2009a. "Special Issue 2007 in Natural Hazards on "Modelling and Simulation of Dangerous Phenomena, and Innovative Techniques for Hazard Mapping and Mitigation". Natural Hazards 50 (3): 409411. doi:10.1007/s11069-009-9420-1.

Iovine, G., and M. F. Sheridan. 2009b. "Preface. Special Issue 2006 in Computers and Geosciences on Modelling and Simulation of Dangerous Phenomena, and Innovative Techniques for Hazard Mapping and Mitigation." Computers \& Geosciences 35 (5): 869-870. doi:10.1016/ S0098-3004(09)00094-6.

Iovine, G., M. F. Sheridan, and S. Di Gregorio. 2006. "Guest Editorial. Computer Simulation of Natural Phenomena for Hazard Assessment." Computers \& Geosciences 32 (7): 859-860. doi:10.1016/j.cageo.2005.12.001.

Iovine, G., M. F. Sheridan, J. Huebl, M. Pastor, C. Aubrecht, and S. Scheer. 2012. "Preface. Innovative Modelling Approaches for Disaster Risk Reduction." Physics and Chemistry of the Earth 49: 1-2. doi:10.1016/j. pce. 2012.08.004.

Kappes, M., M. Keiler, K. von Elverfeldt, and T. Glade. 2012. "Challenges of Analyzing Multi-hazard Risk: A Review." Natural Hazards 64 (2): 1925-1958. doi:10.1007/s11069012-0294-2.

Kechaidou, M. G., GCh. Sirakoulis, and E. M. Scordilis. 2013. "Modelling Real Earthquake Activity with Reverse Engineering Based on Evolutionary Computation Methods." Georisk 7 (4): 275-288.

Nastos, P. T., and I. T. Matsangouras. 2013. "A Proposed Atmospheric Hazards Early Warning System (AHEWS) Incorporated in the New Structure of the Greek Regional Administration 'Kallikratis'." Georisk 7 (4): 267-274.

Osaragi, T. 2013. "Towards an Incombustible City: Building Reconstruction in Potential and Probable Fireproofing of Urban Lots." Georisk 7 (4): 289-299.

Parise, M., and G. Iovine. 2009. "Preface to the Special Issue on 'Innovative Approaches for Evaluating Landslide
Hazard and Risk." Geografia Fisica e Dinamica Quaternaria 32 (2): 179-181.

Parise, M., G. R. Iovine, P. Reichenbach, and F. Guzzetti. 2012. "Introduction to the Special Issue 'Landslides: Forecasting, Hazard Evaluation, and Risk Mitigation."' Natural Hazards 61 (1): 1-4. doi:10.1007/s11069-0119991-5.

Sanchez, M., M. Pastor, and M. Romana. 2013. "Modelling of Short Runout Propagation Landslides and Debris Flows." Georisk 7 (4): 250-266. 